\title{
Erratum to: Contribution of allochthonous resources to breeding in a high-arctic avian predator
}

\author{
Jean-Rémi Julien • Pierre Legagneux $\cdot$ \\ Gilles Gauthier · R. I. Guy Morrison • \\ Jean-François Therrien · Joël Bêty
}

Published online: 4 July 2014

(C) Springer-Verlag Berlin Heidelberg 2014

Erratum to: Polar Biol (2014) 37:193-203

DOI 10.1007/s00300-013-1423-4

The bar showing details for 'Low' under 'Anthropogenic' in Fig. $3 \mathrm{a}$ was missing in the original publication. The complete Fig. 3 is shown below.

The online version of the original article can be found under doi:10.1007/s00300-013-1423-4.

J.-R. Julien · G. Gauthier · J.-F. Therrien

Département de biologie and Centre d'études nordiques,

Pavillon Vachon, Université Laval Québec, 1045 avenue de la

Médecine, Québec City, QC G1V 0A6, Canada

P. Legagneux $(\varangle) \cdot$ J. Bêty

Département de biologie and Centre d'études nordiques,

Université du Québec à Rimouski, 300 Allée des Ursulines,

Rimouski, QC G5L 3A1, Canada

e-mail: legagneux@gmail.com

R. I. Guy Morrison

Canadian Wildlife Service, National Wildlife Research Centre,

Carleton University, 1125 Colonel By Drive (Raven Road),

Ottawa, ON KJA OH3, Canada

Present Address:

J.-F. Therrien

Hawk Mountain Sanctuary, 410 Summer Valley Road,

Orwigsburg, PA 17961, USA 

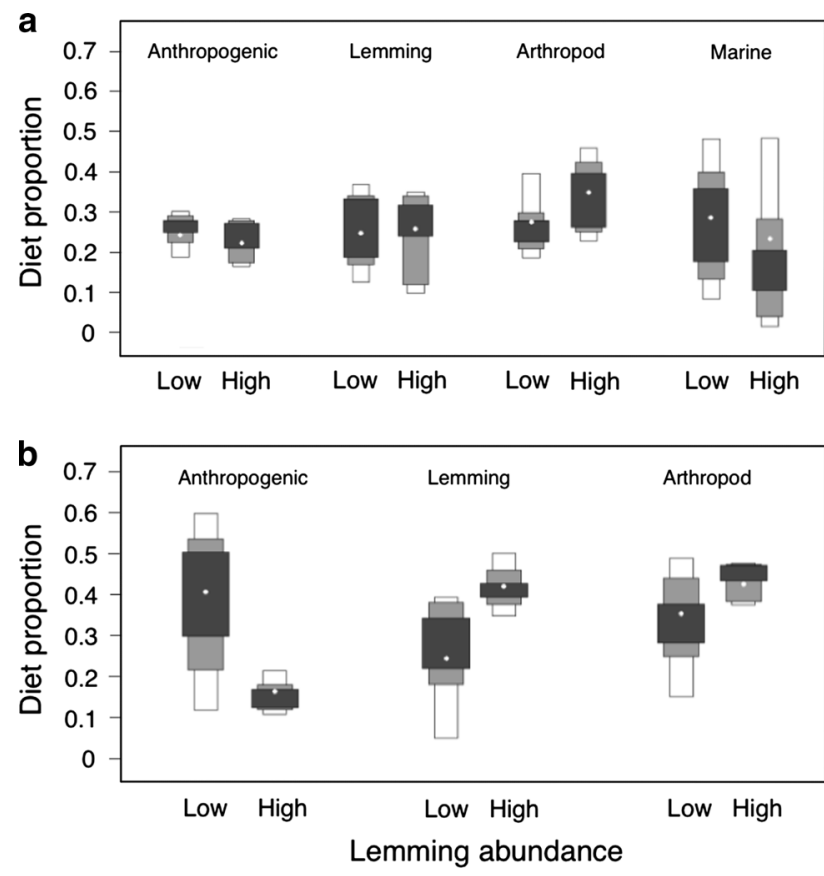

Fig. 3 Diet reconstruction using SIAR mixing models based on plasma isotopic signatures of long-tailed skuas at Alert in years of high (2003) and low (2008) lemming abundance. In upper part, a birds caught at the sewage outfall stream (30 May to 23 June; 2003 $n=10$ and $2008 n=27)$. In lower part, $\mathbf{b}$ birds caught at their nests (3-11 July $2003 n=7$ and $2008 n=10$; marine subsidies were excluded from this specific analysis, see "Materials and methods" section for details). Median (white dot), 50, 75, and $95 \%$ credible intervals (dark gray, light gray, and white boxes, respectively) of the probability distributions of food proportions in diet are presented 